\title{
Cataract surgery today and 20 years ago
}

\begin{abstract}
Introduction. Cataract surgery is one of the most important surgical procedures in ophthalmology.

Aim. The aim of this study is to compare cataract surgeries performed in 1994 and 2014.

Material and methods. A retrospective analysis of 100 cataract procedures in 1994, as well as a total of 100 cataract procedures performed in 2014. The authors considered the following factors: age, sex, vision acuity, cataract type, preoperative patient preparation, intra- and postoperative complications, and total hospitalization time.

Results. Back in 1994, extracapsular cataract extraction (ECCE) was the most common treatment technique. It caused more intraoperative complications (46) and postoperative complications (38) and longer total hospitalization time (9.25 days \pm 3.25 SD). In 2014, all procedures were performed using phacoemulsification. As a result, the number of intraoperative (20) and postoperative (14) complications has dropped significantly. Total hospitalization time was also reduced (1.53 days $\pm 1.08 \mathrm{SD})$.

Conclusions. Phacoemulsification significantly improved cataract treatment. This method is much safer and more effective than ECCE.
\end{abstract}

Keywords: cataract, phacoemulsification, ECCE, cataract surgery complications.

DOI: $10.1515 /$ pjph-2015-0013

\section{INTRODUCTION}

According to the World Health Organization (WHO), there are 285 billion people worldwide with visual impairment, of whom 39 billion are blind. Most visual impairment is caused by uncorrected refractive errors $(43 \%)$ and cataract (33\%), yet the cataract remains the leading cause of blindness in the world (51\%) [1].

In Poland, according to the Central Statistical Office (GUS) data for the year 2004, there were 773.000 people with cataract ( $2.4 \%$ of total population). Cataract mostly affects people over 50, with women being affected more frequently than men [2] (Table 1).

Using the data on cataract epidemiology, researchers produced a prognosis of the number of patients with cataracts in Poland in the future. By 2035, the number of patients

TABLE 1. The number of people with cataract in Poland.

\begin{tabular}{lccccc}
\hline \hline \multirow{2}{*}{ Category } & \multicolumn{5}{c}{ Age group } \\
\cline { 2 - 6 } & $\mathbf{1 5 - 2 9}$ & $\mathbf{3 0 - 4 9}$ & $\mathbf{5 0 - 6 9}$ & $\mathbf{7 0 +}$ & Total \\
\hline Men $\left[1 \times 10^{3}\right]$ & 1.3 & 15.3 & 81.0 & 131.0 & 228.5 \\
\hline Women $\left[1 \times 10^{3}\right]$ & 2.6 & 21.2 & 171.3 & 349.1 & 544.1 \\
\hline Both $\left[1 \times 10^{3}\right]$ & 3.9 & 36.3 & 252.3 & 480.1 & 772.6 \\
\hline Morbidity & $0.0 \%$ & $0.3 \%$ & $3.0 \%$ & $13.9 \%$ & $2.4 \%$ \\
\hline
\end{tabular}

Source: GUS [2] with cataracts is expected to increase by nearly $50 \%$ and will reach 1.3 billion, unless more effective cataract surgery techniques are developed. This increase will be caused by the fact of ageing society [3].

Therefore, cataract surgery is one of the most needed and most commonly performed surgical procedures in ophthalmology. The purpose of the treatment is to improve vision, which significantly affects the patients' quality of life. Interestingly enough, it is believed that cataract surgery is the most effective procedure in medicine as a whole, as measured by its effectiveness quotient of the costs for the improvement in quality of life. Advances in medicine and technological developments led to the way qualifications of patients are determined, as well as the and outcome of performed operations within a short period of time.

\section{AIM}

The aim of this study was to compare cataract surgeries performed in 1994 in the Department of Ophthalmology to those performed in 2014 in the Clinic of Diagnostics and Microsurgery of Glaucoma, Medical University, Lublin, Poland. Our goal was to show the differences in certification and preparation of patients, as well as the differences related to the course and effects of treatments separated by two decades of changes.

Department of Diagnostics and Microsurgery of Glaucoma, Medical University, Lublin, Poland 


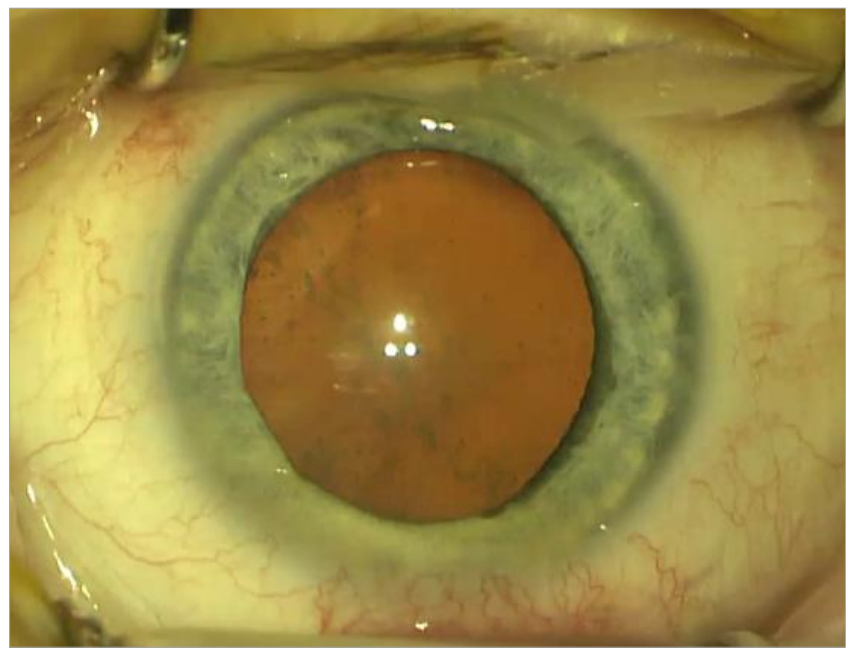

FIGURE 1. Initial cataract.

\section{MATERIAL AND METHODS}

We performed a retrospective examination of 100 randomly selected patients from 1994 and 100 randomly selected patients from 2014. Both groups comprised people who had undergone cataract surgery. The following criteria were taken into consideration: patients' age and sex, type of surgery, anaesthesia and intraocular lens implantation, best-corrected visual acuity (BCVA) before the surgery and during the 7 days following it, methods of preoperative patient preparation. Furthermore, the cataract grade and complicating factors were evaluated, intraoperative and postoperative complications, as well as the need for additional surgery. Attention was also drawn to the total hospitalization length and the time span between the hospital admission and performing the cataract surgery.

\section{RESULTS}

The 1994 patient group consisted of 53 men and 47 women aged between 43 and 89 years (with a mean age $68.1 \pm 10.7 \mathrm{SD})$. Twenty years later, the group consisted of 61 men and 39 women, aged between 33 and 92 years (mean age $72.9 \pm 9.2 \mathrm{SD}$ ). There were 58 right eyes and 42 left eyes operated in 1994 and 49 right eyes and 51 left eyes operated in 2014. In 2014 all cataract surgeries were performed with phacoemulsification (Fako) technique, while in 1994, 27 procedures were performed with Fako, 71 procedures were performed with extracapsular cataract extraction (ECCE) and 2 procedures with intracapsular cataract extraction (ICCE) technique. All procedures were performed under local anaesthesia, with the sole use of retrobulbar injection in 1994. Twenty years later, 27 patients received topical anaesthesia supplemented by intracameral lidocaine, and 71 patients received peribulbar injection. Artificial intraocular lens (IOL) was implanted to the posterior capsule in 98 cases, in 1 case to the sulcus and one procedure was performed without the implant in 2014. In 1994, 88 IOLs were implanted into the posterior capsule, 1 to the sulcus, 5 to the anterior chamber and in 6 cases no IOL was implanted.

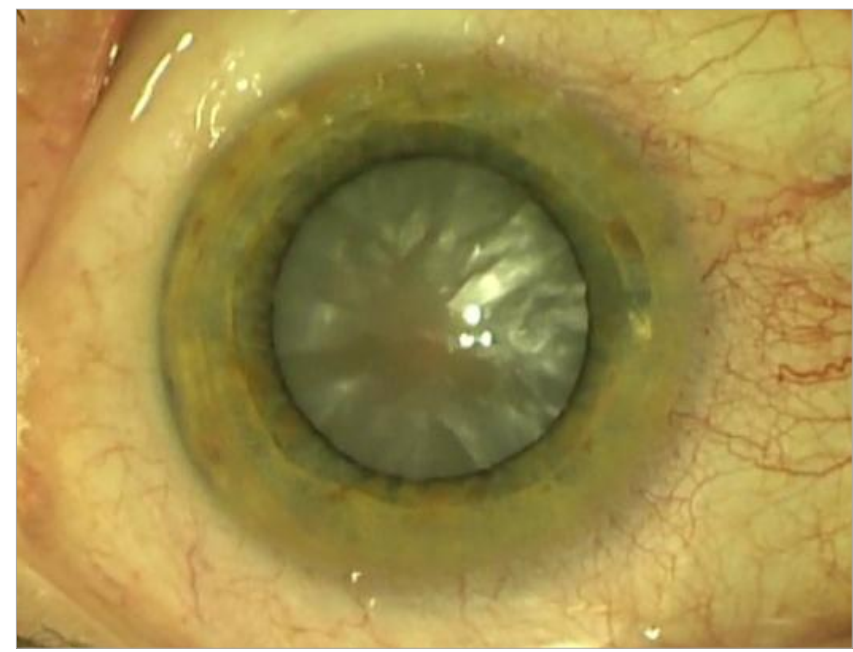

FIGURE 2. Mature cataract.

In 1994, BCVA averaged $0.024 \pm 0.035 \mathrm{SD}$ before and $0.29 \pm 0.21 \mathrm{SD}$ after cataract surgery, wherein the improvement of vision of one or more lines in Snellen chart was reported in $95 \%$, no change in $2 \%$ and deterioration concerned $3 \%$ of patients. Two decades later, BCVA before the procedure was on average $0.26 \pm 0.25 \mathrm{SD}$, with $0.49 \pm 0.33 \mathrm{SD}$ after the procedure. There was a vision improvement of one or more lines in Snellen chart in $81 \%$, no changes in $8 \%$ and a deterioration in $11 \%$ of cases.

The most common type of cataract treated in 1994 was mature cataract - $60 \%$ (including 25 cases of hypermature cataract), only $40 \%$ were initial cataracts, and $26 \%$ among all cases were reported as complicated cataracts (Figure 1,2). In 2014 , the dominant type of cataract was initial cataract $-93 \%$, only $7 \%$ were mature cataracts (including 1 case of hypermature cataract) and $59 \%$ of all cataracts were marked as complicated. Table 2 contains a list of reasons for qualifying a cataract as complicated.

TABLE 2. Reasons to qualify a cataract as complicated.

\begin{tabular}{lcc}
\hline \multicolumn{1}{c}{ Complicating factors } & $\mathbf{1 9 9 4}$ & $\mathbf{2 0 1 4}$ \\
\hline Glaucoma & 3 & 34 \\
\hline Pseudoexfoliation syndrome & 2 & 7 \\
\hline Myopia & 9 & 15 \\
\hline Hyperopia & 2 & 3 \\
\hline Diabetic retinopathy & 14 & 24 \\
\hline Others & - & 2 \\
\hline Total* & $30 *$ & $85^{*}$ \\
\hline
\end{tabular}

* some eyes had more than one complicating factor

The report on the operations and postoperative observations indicated an incidence of various complications. The most common complications in 2014 included posterior capsule tear and a narrow or constricting pupil during surgery. In 1994, other frequently described complication was "vis a tergo" (pressure of vitreous from behind causing anterior chamber shallowing) (Table 3 ).

Corneal oedema was the most common post-operative (up to 7 days after cataract surgery) complication - it occurred in $15 \%$ of cases in 1994 and $8 \%$ of cases in 2014 . 
Additionally, in 1994, inflammation in anterior chamber $8 \%$ and residual cortical matter in anterior chamber $-6 \%$ were often found. Twenty years later, there was a rise of $4 \%$ in intraocular pressure (IOP), as well as 1 case of malignant glaucoma was found (Table 4).

There was a huge number of eyes with complicated cataract, which often required additional surgical procedures, that were performed during the cataract surgery. In 1994, the most common intervention were anterior vitrectomy 5 cases and sectoral iridectomy -3 cases. Occasionally,

TABLE 3. Intra-operative cataract surgery complications.

\begin{tabular}{lcc}
\hline \hline \multicolumn{1}{c}{ Complication } & $\mathbf{1 9 9 4}$ & $\mathbf{2 0 1 4}$ \\
\hline Posterior capsule tear & 9 & 6 \\
\hline Vitreous loss & 9 & 2 \\
\hline Dislocation of nucleus to vitreous cavity & - & 1 \\
\hline Anterior chamber shallowing & 11 & 2 \\
\hline Narrow pupil & 10 & 6 \\
\hline Hyphema & 4 & - \\
\hline Iris damage & 3 & - \\
\hline Regional zonular dialysis & - & 1 \\
\hline Descemet's membrane stripping & - & 1 \\
\hline IFIS (intra-operative floppy iris syndrome) & - & 1 \\
\hline Total * & $46^{*}$ & $20^{*}$ \\
\hline
\end{tabular}

* some eyes had more than one complication

TABLE 4. Post-operative cataract surgery complications.

\begin{tabular}{lcc}
\hline \hline \multicolumn{1}{c}{ Complication } & $\mathbf{1 9 9 4}$ & $\mathbf{2 0 1 4}$ \\
\hline Corneal oedema & 15 & 8 \\
\hline Inflammation in anterior chamber & 8 & - \\
\hline Residual cortical matter & 6 & - \\
\hline Hyphema & 2 & - \\
\hline Vitreous in anterior chamber & 3 & - \\
\hline Too loose sutures & 3 & - \\
\hline Intraocular pressure rise & - & 4 \\
\hline Malignant glaucoma & - & 1 \\
\hline Dislocation of intraocular lens & 1 & 1 \\
\hline Total* & $38^{*}$ & $14^{*}$ \\
\hline
\end{tabular}

* some eyes had more than one complication

TABLE 5. Hospitalization time of patients with cataract.

\begin{tabular}{lcc}
\hline \hline $\begin{array}{c}\text { Time from admission to hospital } \\
\text { to performing cataract surgery }\end{array}$ & $\mathbf{1 9 9 4}$ & $\mathbf{2 0 1 4}$ \\
\hline 0 (surgery at the same day) & 1 & 85 \\
\hline 1 day & 26 & 13 \\
\hline 2 days & 37 & - \\
\hline 3 days & 5 & 1 \\
\hline 4 days & 9 & 1 \\
\hline 5 days & 7 & - \\
\hline 6 days & 10 & - \\
\hline 7 days & 2 & - \\
\hline 8 days & 3 & - \\
\hline Total days of hospitalization & $9.25 \pm 3.25 \mathrm{SD}$ & $1.53 \pm 1.08 \mathrm{SD}$ \\
\hline
\end{tabular}

reports included synechiolysis (adhesions release) - 1 case and iris repair - 1 case. In 2014, synechiolysis was the most common additional procedure at the time of cataract surgery -5 cases and anterior vitrectomy -2 cases. There was also one case of posterior capsulotomy, after posterior capsule rupture without vitreous loss described.

Within the week following the initial cataract surgery, there was a need for a few additional interventions related to previously recorded complications. They concerned $4 \%$ of eyes in 1994 and 3\% of operated eyes in 2014. In the first case, surgeons performed $1 \mathrm{IOL}$ reposition, 1 corneoscleral sutures exchange, 1 anterior vitrectomy and 1 procedure of anterior vitrectomy with IOL removal from posterior chamber and secondary IOL implantation to anterior chamber. In 2014, supplementary interventions were 1 trabeculectomy (cataract surgery was in this case a first stage of antiglaucoma treatment), 1 anterior vitrectomy with goniosynechiolysis and anterior chamber reconstruction (the case of malignant glaucoma), and 1 pars plana vitrectomy to remove nucleus fragments from vitreous cavity.

There were significant differences between the hospitalization time in 1994 and 2014. It ranged from 4 to 23 days (average 9.25 $\pm 3.25 \mathrm{SD}$ ) in 1994, whereas two decades later, $85 \%$ of the operations were performed in one day. The time of patient preparation for the planned cataract removal is another important issue. Back in 1994, the number of days between the hospital admission until performing surgery was up to 8 (mean $2.84 \pm 1.96 \mathrm{SD}$ ) (Table 5).

\section{DISCUSSION}

The analysis of collected results reveals significant differences concerning numerous ways of performing cataract surgeries between 1994 and 2014. However, it needs emphasizing that the year of 1994 was crucial in the Department of Ophthalmology in Lublin, both in terms of surgical methods and preparing patients for the surgery.

Before 1994, the ECCE was the most common surgical technique, while phacoemulsification had yet to be introduced as a modern technique of extracapsular cataract removal. Using phacoemulsification was associated with main incision size reduction and different method of nucleus removal. The ECCE was performed through a 9-11 mm superior corneoscleral incision, the nucleus was removed by manually pressure and extraction from the bag of the lens and wound was closed with sutures [4] (Figure 3). Typically, the wound was closed with interrupted or continuous 10-0 nylon sutures. During phacoemulsification a surgeon was using a tip vibrating at ultrasonic frequencies to the nucleus fragmentation and aspiration, without a necessity to make a large cut to remove nucleus outside in one piece. In 2014, all procedures were performed through a $2.6-2.2 \mathrm{~mm}$ incision without the need for sutures (Figure 4). These changes considerably accelerated the healing process, decreased postoperative inflammation and astigmatism as well as reduced incidence of complications related to the surgical wound [5].

A change in procedures on preparation of patients before surgery was another important step forward. In the past, the hospital admission was followed by collecting conjunctival cultures, later used in bacteriological tests. If the result 


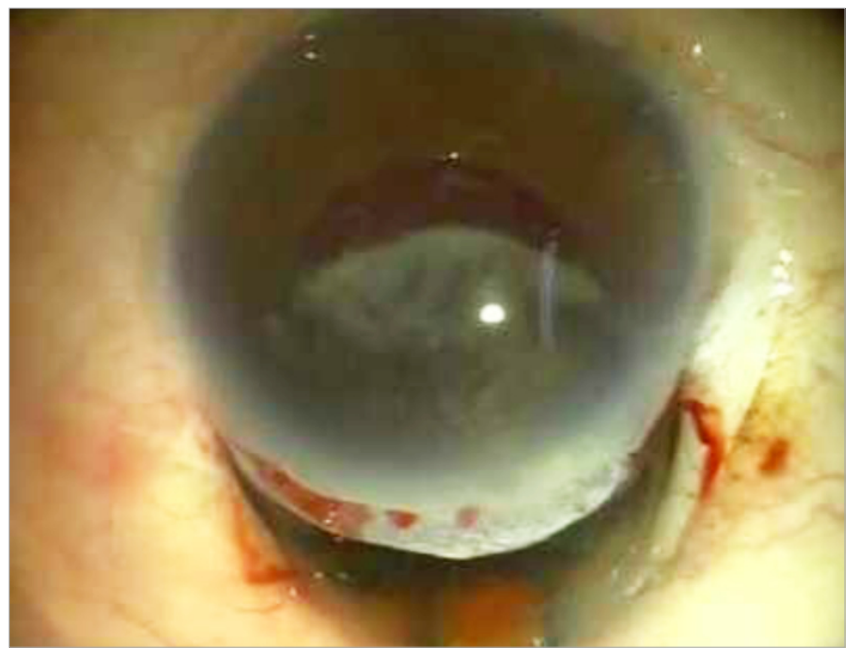

FIGURE 3. ECCE - removing of the nucleus through $11 \mathrm{~mm}$ incision.

differed from the physiological flora, doctors commenced topical treatment. Only in case of negative preoperative cultures, the patient was qualified for a surgery. In addition, a set of 3 consultations was required - dental, otolaryngological examination and internal medicine, which contained no objection to the proposed operation. Therefore, a number of collateral diagnostic tests was carried out, including chest X-ray, ECG, blood count and biochemical analysis. They were required for the issue of mentioned reviews. The whole procedure was designed to prevent complications, including endophthalmitis and vision loss. At the same time, however, the length of stay in the hospital has increased significantly - sometimes it amounted to 23 days, especially when combined with a treatment of postoperative complications (Table 5). In 1994, they began to modify the existing recommendations. The studies have shown that the discontinuation of examining preoperative bacterial cultures did not increase the incidence of intrabulbar infections following cataract surgery [6]. The use of preoperative povidone-iodine instillation proved to be the most recommended with regard to bacterial endophthalmitis prophylaxis in cataract surgery $[7,8]$. Consequently, mandatory consultation of dentist, laryngologist and routine conjunctival cultures were also discontinued. As a result, the time to prepare patients for surgery and the total duration of hospitalization were significantly shortened.

By 2014, the procedures have changed, in line with European Society of Cataract and Refractive Surgery (ESCRS) guidelines [9]. Perioperative prophylaxis involved topical application of an antibiotic drops into the conjunctival sac immediately before surgery and injection of $1 \mathrm{mg}$ of Cefuroxime into the anterior chamber at the end of cataract surgery. The common element remains preventive application of povidone-iodine on the cornea surface, to the conjunctival sac and on the skin in peribulbar area. Improved safety of surgical procedures allowed for changing the organization of treatment and shortened the stay of patients in the clinic to one day in $85 \%$ of cases. The increased length of hospitalization was mainly due to the advanced age of the patient, difficulties with travelling or need for dealing with complications.

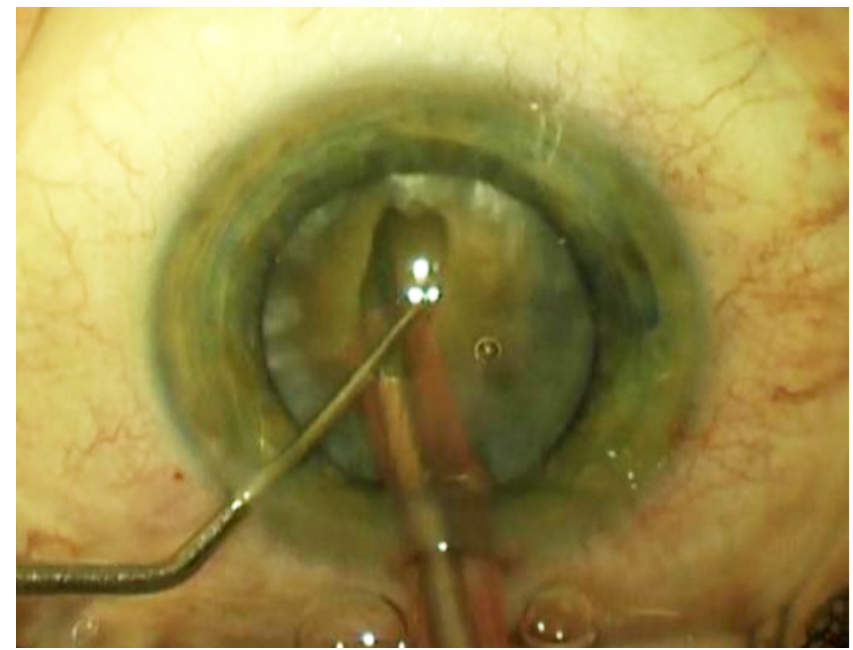

FIGURE 4. Fako - phacoemulsification of the nucleus through $2.2 \mathrm{~mm}$ incision.

In the past 20 years, the profile of an average patient undergoing the operation has also changed. It might be worth noticing that the average age of a patient in 1994 was lower than in 2014. Also, the severity of cataract and associated poor initial visual acuity was greater. In 1994, most of the procedures were mature $(60 \%)$ or even hypermature $(25 \%)$ cataracts removal. This is why the vision before surgery was worse and surgery performance more difficult. As a consequence, the risk of complications was higher which led to poorer final vision results. There might be numerous reasons for that, like a greater number of neglected patients, poor access in eye care or lower quantity of performed procedures and the resulting qualification of the most severe cases only. Extensive experience of surgeons probably reduced the number of possible complications, nevertheless there were twice as many adverse events in relation to the procedures performed 20 years later.

In 2014, the eyes qualified for cataract surgery had much better initial BCVA. In cases where cataract removal was performed as antiglaucoma procedure $(5 \%)$, the initial visual acuity ranged from 0.1 to 1.0 . It was not only the surgery indications that changed but also the patients' expectations. A desire to maintain social and professional activity pushed patients to report for the intervention with less severity of lens opacities ( $93 \%$ of initial cataracts). The main factors included easier access to eye care, increased health awareness and increased safety of the treatment.

Despite advanced surgical techniques and modern equipment peri- and postoperative, some complications were still encountered. One issue that could have had a significant impact on this situation was the amount of eyes with complicated cataract directed to the Department of Ophthalmology as a reference center. In 1994, the complicated cataract accounted for $26 \%$, and by 2014 as much as $59 \%$ of cases. One of the reasons for this increase was that the number of other ophthalmological centers specializing in cataract surgery has risen significantly. They handle the majority of simple cases and direct others to the University Hospital. In addition, modern diagnostic methods, as well as the progress in medicine itself, provide greater recognition of eye diseases. The improved systems and surgical techniques encourage 
patients and doctors to treat even the most complex cases. As a result, difficult and complicated cases were handled by experienced professionals, which, unfortunately, did not prevent some complications.

The number of patients with glaucoma, who were qualified for cataract surgery in 1994 and 2014, should also be looked at. In 1994, there were only 3 cases, while in 2014 there were as many as 34 cases. We can only speculate that the reasons were as follows: improved diagnostic methods, as well as the fact that the Clinic of Diagnostics and Microsurgery of Glaucoma in Lublin was focused on such actions.

Variations found in outpatient records 21 years ago make long-term observations of improvement or deterioration of vision and eventual complications in operated eyes impossible. Therefore for reliable comparison we analyzed in this study the same follow-up period of 2014, despite a much richer resource of current data. The disadvantage of a retrospective assessment is also inability to verify credibility of surgical reports and clinical notes. It is difficult to suspect no intraocular pressure increase in an eye with inflammation or residual cortical matter in the anterior chamber or no additional causes of vision impairment in eye after an operation performed according to the documentation without complications. Despite these difficulties, the collected data reveal a lot of interesting information and an overview of the changes that occurred between the studied years.

\section{CONCLUSIONS}

Cataract surgery remains one of the most important surgical procedures in ophthalmology. Improvement of visual acuity and the ability to function independently are essential for improving the quality of patients' life. Extensive changes that occurred in 20 years in diagnosis, pre- and post-operative procedures and technique of cataract removal, are not found in any other field of medicine. Resignation of unnecessary additional tests, reducing the size of the incision from 12 to $2.2 \mathrm{~mm}$, no need to wound sutures and change in the surgical method resulted in increased safety and faster visual rehabilitation. This enabled reducing the time needed for preparing and handling the patient to 1 day, which, in turn, as a consequence reduced the total hospitalization time by 6 times.

A complete transformation of ophthalmic surgery routine has opened the door to outpatient cataract surgery. As a result, treating larger groups of patients, reducing waiting lists and improving the quality of life of patients, is now possible. All this is achieved with the use of financial resources proportionate to those offered two decades ago.

\section{REFERENCES}

1. Pascolini D, Mariotti SP. Global estimates of visual impairment: 2010. Br J Ophthalmol. 2012; 96:614-8.

2. Archiwum GUS. Stan zdrowia ludności Polski w 2004 r. [http://www. stat.gov.pl/gus/5840_658_PLK_HTML.htm?action=show_archive]

3. Dostęp do opieki okulistycznej w Polsce. Podejście systemowe. Najważniejsze problemy związane z dostępem doświadczeń okulistycznych. CEESTAHC 2012. [http://www.ceestahc.org/pliki/nasze_publikacje/raporty/Dostep_do_opieki_okulistycznej_w_Polsce.pdf]

4. Soczewka i zaćma. Basic and $\bar{C}$ linical Science $\bar{C}$ Course. Section 11. 2005-2006.

5. Żarnowski T, Chmiel M, Haszcz D, Zagórski Z. Evaluation of astigmatism and blood-aqueous barrier breakdown following procedures in the anterior eye segment. Klin Oczna. 1998;100(1):11-4.

6. Szymulska M, Haszcz D, Rakowska E, Zagórski Z. Wartość badań bakteriologicznych w chirurgii zaćmy. Klin Oczna. 1996;98:125-7.

7. Apt L, Isenberg SJ, Yoshimori R, et al. The effect of povidone-iodine solution applied at the conclusion of ophthalmic surgery. Am J Ophthalmol. 1995; 119:701-5.

8. Ciulla TA, Starr MB, Masket S. Bacterial endophthalmitis prophylaxis for cataract surgery: an evidence-based update. Ophthalmology. 2002;109:13-24.

9. Barry P, Cordovès L, Gardner S. Wytyczne ESCRS dotczące profilaktyki i leczenia zapalenia wnętrza gałki ocznej po operacji zaćmy: dane, dylematy i wnioski 2013. [http://www.escrs.org/endophthalmitis/guidelines/POLISH.pdf]

\section{Corresponding author}

Agnieszka Rozegnał-Madej

1 Chmielna Str., 20-079 Lublin

Tel: +48 606-940-508

E-mail: madejaga@o2.pl

Photographic documentation supplied by the Authors. 